Research Article

\title{
Decision Method of Bridge Deck Pavement Maintenance Based on the Decision Maker's Objective
}

\author{
Xiaofei Liang $\left(\mathbb{D}\right.$, Jun Shi $\mathbb{D}^{\text {, }}$, and Zhongmei Li \\ School of Civil and Architectural Engineering, Shandong University of Technology, Zibo 255000, China \\ Correspondence should be addressed to Jun Shi; sjun@sdut.edu.cn
}

Received 28 January 2021; Revised 7 March 2021; Accepted 22 May 2021; Published 7 June 2021

Academic Editor: Luigi Aldieri

Copyright (c) 2021 Xiaofei Liang et al. This is an open access article distributed under the Creative Commons Attribution License, which permits unrestricted use, distribution, and reproduction in any medium, provided the original work is properly cited.

\begin{abstract}
The performance of reinforced concrete bridge deck pavement will be gradually reduced with the increase of operation time, so the reasonable maintenance measures should be taken to ensure the performance and safety of the bridge structures. The objectives and their hierarchical structures from both state position and enterprise position of the decision makers in bridge engineering decision-making problems were discussed. By the existing deterioration model, this paper studies the bridge operation safety maintenance strategy, establishes the mathematical model of the influence of different degrees of maintenance measures on the structural performance, combines with the cost-benefit theory, establishes the maintenance risk decision criteria for the decision makers with different objectives, and makes the decision on the selection of the bridge deck pavement scheme based on the enterprise position through an example.
\end{abstract}

\section{Introduction}

With the aging of existing bridges, the maintenance of operating bridges becomes very important [1]. Through the detection of the operating bridge, the deterioration of the bridge can be found in time, and the corresponding repair measures can be taken to ensure the safe operation of the bridge $[2,3]$. To make a reasonable inspection and maintenance scheme, several investigations on the bridge operation management under normal degradation conditions have been done. Bian et al. studied the maintenance and reinforcement decision-making of service bridges based on reliability and the influence of maintenance on reliability and maintenance cost [4]. Combining with the optimal reliability of the structure, Qin et al. discussed in detail based on the group decision-making theory [5]. Shao et al. carried out research on structural safety and economic optimization from different angles [6-9]. Based on the two maintenance control indexes of bridge reliability and bridge condition, Cao et al. proposed a multiobjective optimization method for bridge maintenance decision-making, which can comprehensively consider the total maintenance cost, bridge life after maintenance, bridge reliability, and bridge condition $[10,11]$.

Most of the above research studies are based on the reliability theory of bridge safety and take the cost-benefit theory of the lowest cost in the broad sense as the control condition to establish the model to solve the optimal remaining service life of the operating bridge. This kind of research mainly focuses on the theoretical framework construction level, and the research on the maintenance strategy based on time-varying reliability is still in its infancy. Through combining and integrating the existing research results, this paper forms a bridge maintenance decision-making method based on the goal of the decision maker. Based on the deterioration model of reliability index, this method studies the maintenance strategy of bridge operation safety, establishes the mathematical model of the influence of different degrees of maintenance measures on the structural performance, and establishes the maintenance risk decision-making methods for decision makers with different objectives combined with the cost-benefit theory. 


\section{Types and Objectives of Decision Makers}

Decision makers are individuals or groups of individuals who directly or indirectly provide the most important value judgments. In China, the decision-making of bridge construction projects planned by the state needs to be considered from both the state and enterprises [12]. Although the decision makers do not change, their goals and preferences are different due to different starting points. Therefore, they can be regarded as two kinds of decision makers with different natures. In addition, with the continuous exploration of the financing mode of bridge engineering, the private enterprises of bridge engineering have an increasing trend; the decision makers should be the person in charge of the private enterprise, the general meeting of shareholders, or similar institutions, which should be treated as a completely consistent collective and treated as a person. The positions and characteristics of decision makers are shown in Table 1.

The value of the bridge is realized through operation. If the decision maker does not have a clear operation goal, it will lead to the lack of continuity of maintenance measures, which will lead to the lack of understanding of the bridge maintainability and sustainable development ability [13-15]. Different decision makers must scientifically establish the goal of its operation period to realize the value of the bridge. However, no matter the state government units, state-owned enterprises, or private enterprises, the maintenance of bridges should at least include the following aspects:

(i) After maintenance, the bridge must meet a certain safety level

(ii) After maintenance, the bridge must have conditions to reach a certain safe service life

(iii) During and after the maintenance, the influence of the structure on the environment should be controlled

(iv) Maintenance programs minimize or avoid the disruption of traffic

After meeting the basic objectives, as a national capital construction project, the overall goal of the bridge's operation in the national position is to improve people's living standards, while the decision maker in the enterprise position will make value judgment from the interests obtained. In the application, the objective function is represented by money. The objective function selected in this paper has the maximum profit for the enterprise position decision-making and the minimum loss for the state position decisionmaking.

\section{Decision-Making Process}

In theory, different schemes have different risks. It is of positive significance for the safe operation of bridges to consider the cost and subsequent risks when making decisions. Objectively, it is unrealistic to require "zero risk" of bridges. In general, a safe bridge refers to the risk of bridge crash, which is acceptable to individuals or the society
[16-18]. Any bridge has the possibility of damage to varying degrees. It is necessary to take measures to control this possibility within the allowable range. Different measures will lead to different costs and effects. To balance risk reduction and cost, bridge risk decision is required. Conditions for risk decision-making are as follows: setting the target expected by the decision maker, more than two alternatives available, decision-making criteria, the benefit value of each scheme can be calculated, and the probability of failure after the implementation of each scheme can be calculated. The risk decision process is shown in Figure 1.

\section{Deterioration Model}

Reliability (or the probability of failure) is one of the most representative probabilistic structural performance indicators [2]. The reliability of a deteriorating bridge decreases over time due to external loadings and various environmental stressors under uncertainty [20]. Deterioration is a complex process. In this paper, referring to the research results of Frangopol and others [21-23], a two-stage linear model with three parameters (initial reliability index $\beta_{0}$, deterioration initial time $t_{I}$, and deterioration rate $\alpha$ ) is adopted for the reliability index of bridges in the operation period, as shown in Figure 2 and the following equation.

$$
\beta(t)= \begin{cases}\beta_{0}, & 0 \leq t \leq t_{I}, \\ \beta_{0}-\alpha\left(t-t_{I}\right), & t>t_{I} .\end{cases}
$$

The value of $\beta_{0}$ is affected by many factors such as design, material, and construction. According to Cao et al. [10], $\beta_{0}$ is 7.0. The physical deterioration, concrete carbonization, and steel corrosion in the course of bridge operation reduce the reliability of the bridge. Imai and Frangopol [24] took the time when the steel bars in the structure began to rust as the deterioration initial time $t_{I}$, as shown in the following equation:

$$
t_{I}=\frac{\left(c-x_{0}\right)^{2}}{k^{2}},
$$

where $c$ is the concrete cover thickness, $k$ is the carbonation coefficient of concrete, and $x_{0}$ is the carbonation remains.

\section{Maintenance Strategy Model}

Under different maintenance measures, the deterioration process of the bridge structure is very different. For the convenience of analysis, it is assumed that the time interval of preventive maintenance $t_{P}$ is the same; the duration of preventive maintenance effect $t_{P D}$ is the same; each preventive maintenance has the same jump $\gamma$ in reliability; there is $\beta(t) \leq \beta_{0}$ at any time [25].

5.1. Preventive Maintenance Based on Time Control. After the completion of maintenance measures, the bridge will deteriorate along the deterioration rate $\theta$ within the duration of maintenance effect $t_{P D}$, and the maintenance interval $t_{P}$ is required to be less than the duration of maintenance effect $t_{P D}$, such as small-scale repair. $t_{P I} \geq t_{I}$ and $t_{P D} \geq t_{P}$. The 
TABLE 1: The positions and characteristics of decision makers.

\begin{tabular}{|c|c|c|c|}
\hline Organization type & Decision maker & Position of the decision maker & Decision-making basis \\
\hline & Public officials of the state & & \\
\hline State-o & Public officials in enterpr & enterprises' position & \\
\hline Private enterprises & The head of private enterprises & The enterprises' position & Value judgment of the decision maker \\
\hline
\end{tabular}

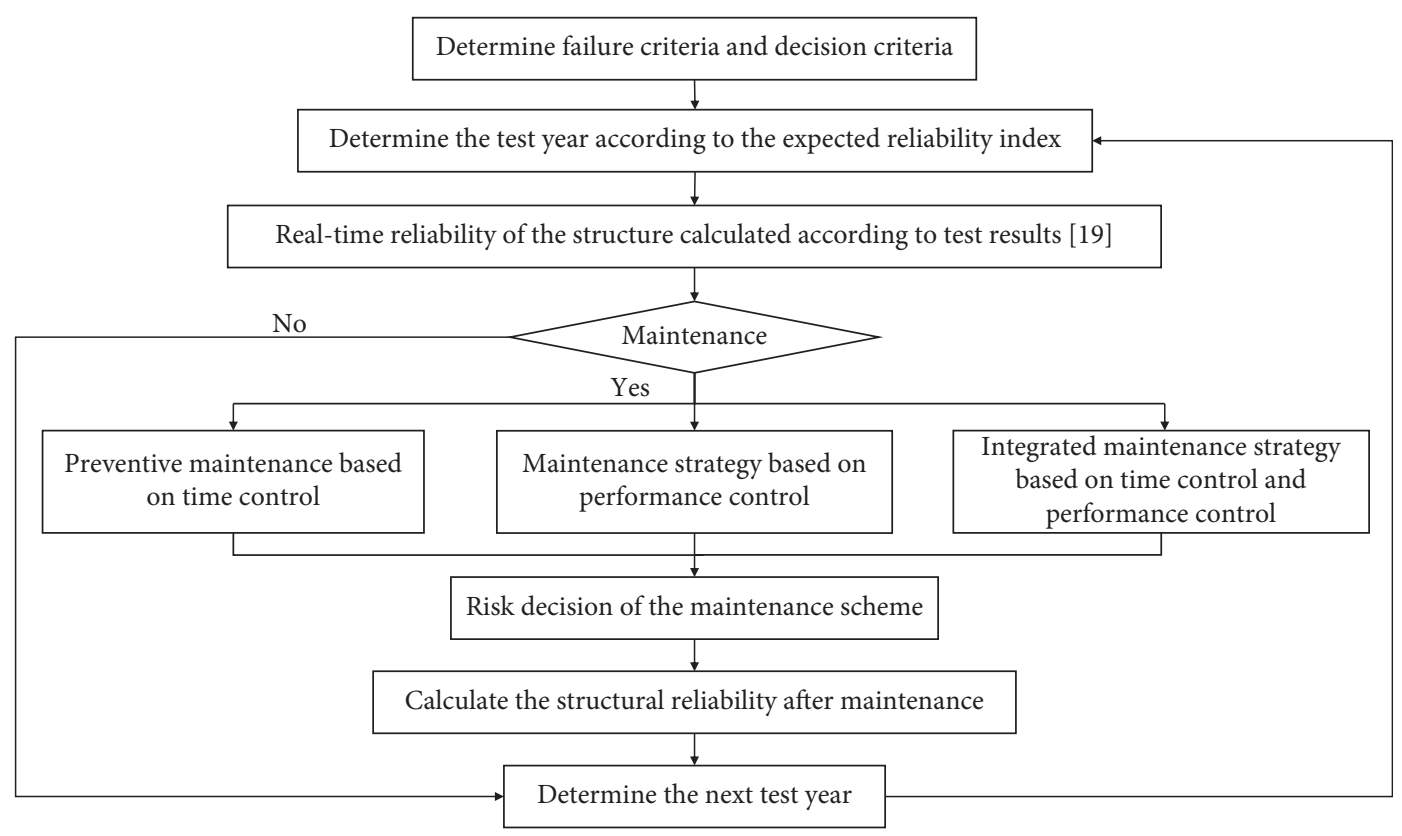

FIGURE 1: Maintenance decision flowchart [19].

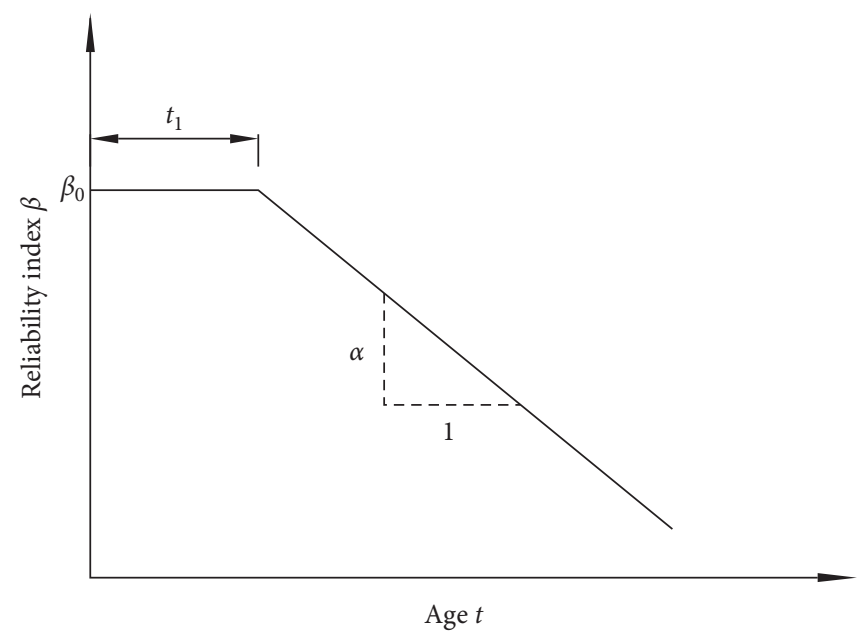

Figure 2: Two-stage linear model of the reliability index. 
change of the reliability index of the bridge is shown in Figure 3, and the expression of deterioration reliability is as follows:

$$
\beta(t)= \begin{cases}\beta_{0}, & t<t_{I}, \\ \beta_{0}-\alpha\left(t-t_{I}\right), & t_{I} \leq t<t_{P I}, \\ \beta_{1}-\theta\left(t-t_{P I}\right), & t_{P I} \leq t<t_{P I}+t_{P}, \\ \beta_{n}-\theta\left\{t-\left[t_{P I}+(n-1) t_{P}\right\},\right. & t_{P I}+(n-1) t_{P} \leq t<t_{P I}+n t_{P},\end{cases}
$$

where $\beta_{1}=-\alpha\left(t-t_{I}\right)+\gamma, t=t_{P I}$, and $\beta_{n}=\beta_{n-1}-\theta t_{P}+\gamma$, $t=t_{P I}+(n-1) t_{P}$.

\subsection{Maintenance Strategy Based on Performance Control.}

Maintenance measures are taken when the performance of the bridge is reduced to the specified allowable performance index, that is, $\beta \leq \beta_{\text {target }}^{\prime}$. The change of the reliability index of the bridge is shown in Figure 4, and the expression of deterioration reliability is as follows:

$$
\beta(t)= \begin{cases}\beta_{0}, & t<t_{I} \\ \beta_{0}-\alpha\left(t-t_{I}\right), & t_{I} \leq t<t_{P I} \\ \beta_{1}-\alpha\left(t-t_{P I}\right), & t_{P I} \leq t<t_{P I}+t_{1} \\ \beta_{n}-\alpha\left\{t-\left[t_{P I}+\sum_{i=1}^{n-1} t_{i}\right]\right\}, & t_{P I}+\sum_{i=1}^{n-1} t_{i} \leq t<t_{P I}+\sum_{i=1}^{n} t_{i}\end{cases}
$$

where $\beta_{1}=\beta_{0}-\alpha\left(t-t_{I}\right)+\Delta \beta_{1}, t=t_{P I}$, and $\beta_{n}=\beta_{n-1}-$ $\alpha t_{n-1}+\Delta \beta_{n-1}, t=t_{P I}+\sum_{i=1}^{n-1} t_{i}$.

5.3. Integrated Maintenance Strategy. In the preventive maintenance strategy based on time control, in order to ensure that the bridge can operate to the design life, the condition of $t_{P I} \geq t_{I}$ and $t_{P D} \geq t_{P}$ should be met, which directly affects the maintenance times. Because the bridge needs to control traffic while it is being maintained, more maintenance reduces the benefits of the bridge. However, when each new maintenance starts, the last maintenance effect is still there, so the damage degree of the bridge is low, the driving comfort is high, and the corresponding single maintenance cost is also low.

The maintenance strategy of performance control has long maintenance cycle, low maintenance frequency, and little influence on traffic revenue. However, when the bridge needs to be maintained, the state of the bridge is at the lowest allowable value, and the bridge often suffers relatively large damage and low driving comfort. In order to ensure the safe operation of the bridge, it is necessary to adopt relatively high-cost reinforcement and renovation measures to improve the performance of the bridge.

The integrated maintenance strategy combining time control and performance control is to adopt time control at the early stage of operation and carry out maintenance and repair after the maintenance effect continues to disappear but before the bridge performance reaches the minimum allowable value. When $t_{P D}<t_{P}$, the deterioration rate of the bridge in $\left[0, t_{P D}\right]$ is $\theta$, and the deterioration rate of the bridge in $\left[t_{P D}, t_{P}\right]$ is $\alpha$. When $\beta \leq \beta_{\text {target }}^{\prime}$, the performance control is adopted to greatly improve the bridge performance. The performance of the bridge changes is shown in Figure 5, and the reliability of deterioration is expressed as follows:

$$
\beta(t)= \begin{cases}\beta_{0}, & t<t_{I}, \\ \beta_{0}-\alpha\left(t-t_{I}\right), & t_{I} \leq t<t_{P I}, \\ \beta_{1}-\alpha\left(t-t_{P I}\right), & t_{P I} \leq t<t_{P I}+t_{1}, \\ \beta_{1}^{\prime}-\alpha\left[t-\left(t_{P I}+t_{P I}\right)\right], & t_{P I}+t_{P D} \leq t<t_{P I}+t_{P}, \\ \vdots & \vdots \\ \beta_{m}-\theta\left\{t-\left[t_{P I}+(m-1) t_{P}\right\},\right. & t_{P I}+(m-1) t_{p} \leq t<t_{P I}+(m-1) t_{p}+t_{P D}, \\ \beta_{m}^{\prime}-\alpha\left\{t-\left[t_{P I}+(m-1) t_{P}\right\},\right. & t_{P I}+(m-1) t_{p}+t_{P D} \leq t \leq t_{P I}+(m-1) t_{p}+t_{m 1},\end{cases}
$$




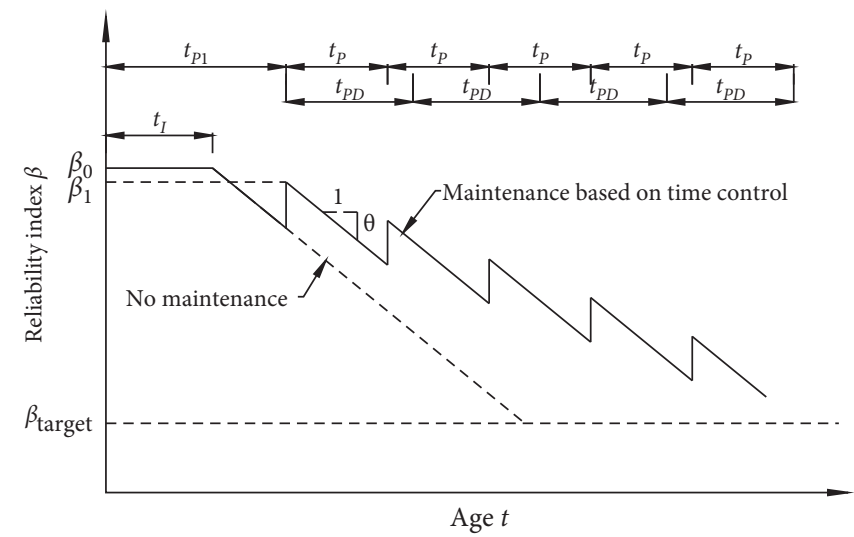

FIgURE 3: Reliability index change chart of the time-based maintenance.

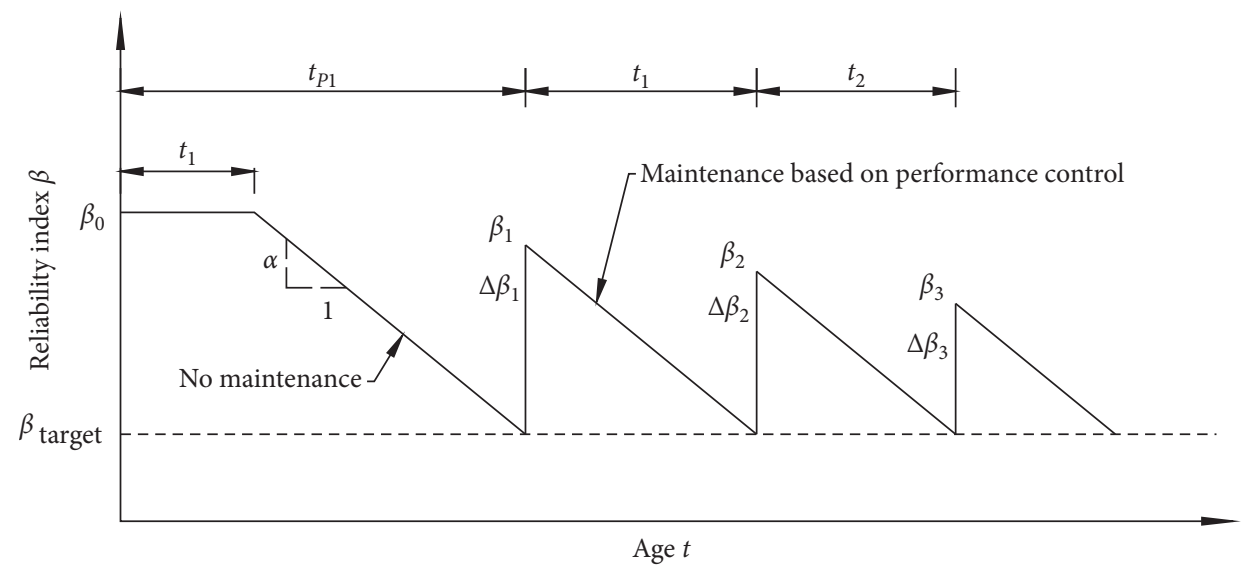

FIGURE 4: Reliability index change chart of the performance-based maintenance.

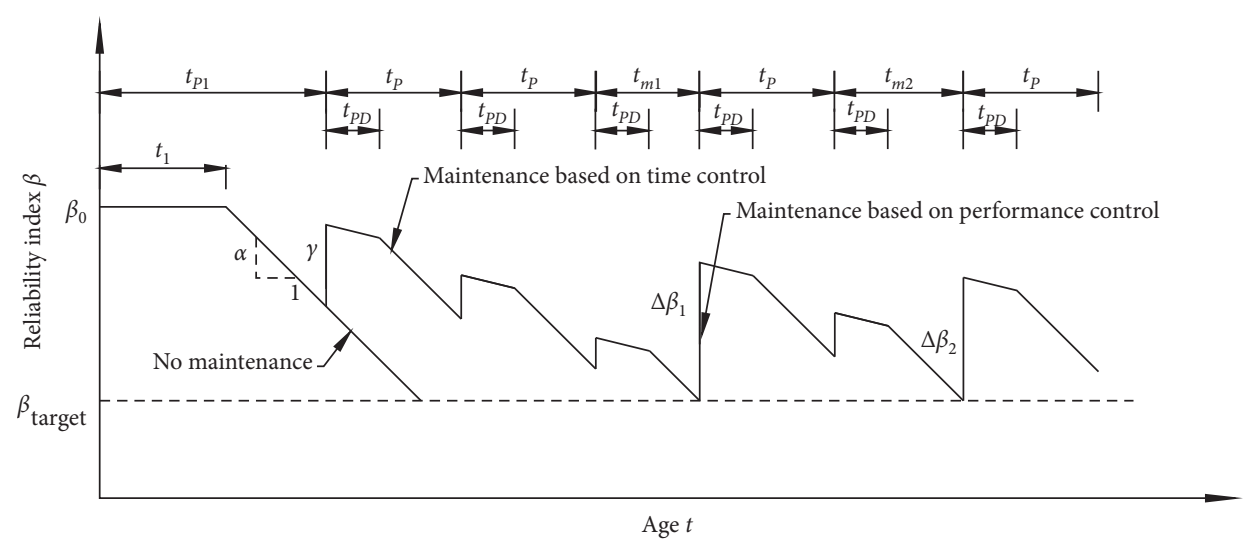

FIGURE 5: Reliability index change chart of the integrated maintenance. 
where $\beta_{1}=\beta_{0}-\alpha\left(t-t_{I}\right)+\gamma, t=t_{P I}, \beta_{1}^{\prime}=\beta_{1}-\theta t_{P D}, \beta_{m}=$ $\beta_{m-1}^{\prime}-\alpha\left\{t-\left[t_{P I}+(n-1) t_{P}\right]\right\}+\gamma$, and $\beta_{m}^{\prime}=\beta_{m}-\theta t_{P D}$.
After $m$ times of maintenance, major maintenance is needed, so the reliability of deterioration is expressed as the following equation:

$$
\beta(t)= \begin{cases}\beta_{n}-\theta\left\{t-\left[t_{P I}+(n-1) t_{P}\right\},\right. & t_{P I}+(n-1) t_{P}+\Delta t \leq t<t_{P I}+(n-1) t_{P}+t_{P D}+\Delta t, \\ \beta_{n}^{\prime}-\alpha\left\{t-\left[t_{P I}+(n-1) t_{P}\right\},\right. & t_{P I}+(n-1) t_{P}+t_{P D}+\Delta t \leq t<t_{P I}+n t_{P}+\Delta t,\end{cases}
$$

where $\beta_{n}=\beta_{n-1}^{\prime}-\alpha\left\{t-\left[t_{P I}+(n-1) t_{P}\right\}+\Delta \beta\right.$ and $\beta_{n}^{\prime}=\beta_{n}$ $-\theta t_{P D}$.

\section{Decision Criteria for Bridge Deck Pavement Maintenance Based on the Decision Maker Objective}

The purpose of decision analysis is to make the "best" decision. Different stances, experiences, and degrees of risk aversion of decision makers determine different "best" decisions, whose essence is to meet decision makers' expectations. Therefore, the decision matrix can be expressed as the following equation [26]:

$$
E(A)^{\operatorname{def}}=\left[\begin{array}{c}
E\left(A_{1}\right) \\
E\left(A_{2}\right) \\
\vdots \\
E\left(A_{m}\right)
\end{array}\right]=\left[\begin{array}{c}
A_{1} \\
A_{2} \\
\vdots \\
A_{m}
\end{array}\right]\left[\begin{array}{ccc}
a_{11} & a_{12} & a_{1 m} \\
a_{21} & a_{22} & a_{2 m} \\
a_{m 1} & a_{m 2} & a_{m n}
\end{array}\right]_{m \times n} .
$$

The decision-making criterion of bridge deck pavement maintenance based on the decision maker's objective is to quantify the corresponding benefits, costs, and losses of each scheme into the economic value. On the premise of ensuring safety, the maximum expectation calculation model is as follows:

$$
\left\{\begin{array}{l}
u\left(A_{\mathrm{opt}}\right)=\max \left\{E\left(A_{i}\right)\right\} \\
\text { s.t. } u\left(A_{\mathrm{opt}}\right) \geq 0 \\
\beta(t) \geq \beta(T) \\
C_{\mathrm{Man}} \leq C_{\mathrm{Man}, m}
\end{array}\right.
$$

where $C_{\text {Man }} \leq C_{\text {Man, } m}$ is the pavement maintenance cost and the allowable maintenance cost.

When the decision-making body is the state, in addition to the charging benefit, more benefits of national economy will be generated during the operation of the bridge. $\mathrm{Na}$ tional economic benefits have no specific material products. Therefore, it is difficult to quantify the benefits brought by bridge operation to the national economy and society and the contribution to the economic development of the whole society or region. In this case, the adoption of the maximum expected benefit criterion will produce relatively unobjective results due to the preference of the decision maker. At this point, the consequence value $\theta_{i k}^{(1)}, \theta_{i k}^{(2)}, \ldots, \theta_{i k}^{(n)}$ only represents the cost $C_{i k}^{(1)}, C_{i k}^{(2)}, \ldots$ and loss $L_{i k}^{(1)}, L_{i k}^{(2)}, \ldots$, but does not contain the benefit $B_{i k}^{(1)}, B_{i k}^{(2)}, \ldots$. Therefore, based on the national position, it should be expressed as follows according to the minimum expected cost criterion:

$$
\left\{\begin{array}{l}
d\left(A_{\text {opt }}\right)=\min \left\{E\left(A_{I}\right)\right\} \\
\beta(t) \geq \beta(T)
\end{array}\right.
$$

\section{Model Validations}

The bridge was completed and opened to traffic in 2001, with an annual growth rate of $8 \%$ and a 25-year concession period. The bridge deck is paved with $8 \mathrm{~cm}$ thick cement concrete. At present, the damage of bridge deck pavement is relatively serious on the whole, and the connection state of some concrete pavement layers and the beam body is poor, which leads to rainwater infiltration into the main beam and affects the safety of the bridge structure. The heavy traffic and damaged road surface increase the risk of traffic accident rate. It is planned to overhaul the bridge deck pavement to ensure the safety of road traffic and bridge structure. Since it is still within the concession period, this paper will refer to equation (9) and make a risk decision on the operation and safety maintenance of the bridge from the standpoint of the enterprise based on the cost-benefit criterion. When the bridge is repaved, double width and half width are each closed, and 2 5 types of passenger and freight vehicles are separated. It is estimated that the proportion of toll loss is $33.1 \%$, and the daily toll loss is about 210,700 yuan. The bridge deck treatment scheme is shown in Table 2 .

The bridge has been in operation for 20 years, and the bridge deck renovation carried out at this time belongs to performance-based bridge maintenance. Therefore, the expression of deterioration can be referred to equation(4). $t_{I}=4[24], t_{P I}=20, t_{P I}=t_{I}+\left(\left(\beta_{0}-\beta_{\text {target }}\right) / \alpha\right), \beta_{0}=7.0[10]$, and $\beta_{\text {target }}=3.7$, so $\alpha=\left(\beta_{0}-\beta_{\text {target }}\right) /\left(t_{P I}-t_{I}\right)=0.21$.

Because the pavement of the renovated bridge deck belongs to protective maintenance, the reliability of the bridge surface after the pavement is installed with ordinary cement concrete is improved to $\beta=4.494$, and the reliability of the bridge surface after the pavement is installed with steel fiber concrete is improved to $\beta=5.263$ [29]. The number of years that bridge deck pavement can maintain its service performance is 7.78 years for schemes $\mathrm{A}$ and $\mathrm{C}$ and 11.44 years for schemes B and D.

In 2019, the total toll will be 216 million yuan, and the benefit value will increase by $8 \%$ in the same year as the traffic volume. According to equations (1) and (7), the calculated result is $E(A)_{A}>E(A)_{B}>E(A)_{D}>E(A)_{C}$. Therefore, from the standpoint of the enterprise, facing the 
TABLE 2: Bridge deck pavement maintenance scheme.

\begin{tabular}{|c|c|c|c|c|}
\hline & Scheme A & Scheme B & Scheme C & Scheme D \\
\hline $\begin{array}{l}\text { Maintenance } \\
\text { mode }\end{array}$ & $\begin{array}{l}8 \mathrm{~cm} \text { thick } \\
\text { ordinary } \\
\text { concrete }\end{array}$ & $8 \mathrm{~cm}$ thick steel fiber concrete & $8 \mathrm{~cm}$ thick quick cement concrete & $\begin{array}{l}6 \mathrm{~cm} \text { thick steel fiber concrete } \\
\text { and MRK }+2 \mathrm{~cm} \text { thick ultrathin } \\
\text { wear layer; steel fiber-reinforced } \\
\text { concrete }(85 \%) \text {; MRK }(15 \%)\end{array}$ \\
\hline $\begin{array}{l}\text { Maintenance } \\
\text { costs }\end{array}$ & $\begin{array}{c}6.14 \text { million } \\
\text { yuan }\end{array}$ & 6.83 million yuan & 17.54 million yuan & 10.28 million yuan \\
\hline $\begin{array}{l}\text { Maintenance } \\
\text { cycle }\end{array}$ & $150 \mathrm{~d}$ & $150 \mathrm{~d}$ & $140 \mathrm{~d}$ & $160 \mathrm{~d}$ \\
\hline Traffic loss & $\begin{array}{c}31.61 \text { million } \\
\text { yuan }\end{array}$ & 31.61 million yuan & 29.50 million yuan & 33.71 million yuan \\
\hline $\begin{array}{l}\text { Maintenance } \\
\text { characteristics }\end{array}$ & $\begin{array}{l}\text { Mature process; } \\
\text { weak tensile and } \\
\text { shear strength }\end{array}$ & $\begin{array}{c}\text { Good crack resistance; good } \\
\text { integrity of the bridge deck, } \\
\text { high toughness, and tensile } \\
\text { strength; steel fibers rust easily } \\
\text { [27] }\end{array}$ & $\begin{array}{l}\text { Time is short; the price is more } \\
\text { expensive; new materials; new } \\
\text { technology; performance and } \\
\text { durability are not widely proven }\end{array}$ & $\begin{array}{l}\text { The landscape effect is good; } \\
\text { good durability; more material } \\
\text { types; complicated construction } \\
\text { technology [28] }\end{array}$ \\
\hline
\end{tabular}

concession period of 5 years, the choice of scheme A is the most appropriate.

Decisions based on national positions are not affected by the concession period. After the bridge deck pavement is renovated, the bridge using schemes $\mathrm{A}$ and $\mathrm{C}$ will need to reinvest in maintenance after 7.78 years of operation, and the total cost and loss of re-repair will inevitably exceed those of other schemes. Therefore, according to equation (9), schemes $\mathrm{B}$ and $\mathrm{D}$ are given priority. The deterioration trend of schemes B and D is the same, and the total cost expenditure of scheme $\mathrm{D}$ is higher than that of scheme B. However, after 11.44 years, the bridge deck pavement in schemes B and D also needs to be renovated again. At this time, scheme D can take a small repair to improve the safety of the bridge deck pavement by milling off the $2 \mathrm{~cm}$ covering and re-covering it with less cost. Therefore, based on the national position, scheme $\mathrm{D}$ is the most appropriate.

\section{Conclusions}

This paper has presented a risk decision method of bridge operation safety maintenance based on the decision maker's goal. The mathematical model of the influence of maintenance measures on the structural performance under different control conditions was established. Combined with the cost-benefit theory, the decision criteria of maintenance risk were established for decision makers with different objectives. Based on this investigation, the following conclusions are drawn:

(i) Based on the analysis of the characteristics and objective hierarchy of different decision makers, a bridge maintenance decision-making method based on decision makers' objectives is proposed by classifying decision makers related to bridge maintenance units and departments into national decision makers and enterprise decision makers.

(ii) Based on the existing deterioration model, the mathematical model of the influence of maintenance measures on the structural performance under different control conditions is established. For bridge maintenance, three maintenance strategies can exist simultaneously. What maintenance mode to take depends on the situation of the maintenance object itself and should be determined according to the maintenance technology and maintenance means, so as to achieve both economic and effective purposes.

(iii) The performance of bridge deck pavement decreases gradually with the increase of operation time, so reasonable maintenance measures should be taken to ensure the safety of the bridge. According to the decision-making process of this paper, for different decision makers' goals, combined with examples, this paper has carried on the risk decision-making of the choice of the bridge deck pavement scheme.

(iv) The risk decision method in this paper can be used for the maintenance management of similar reinforced concrete structures. As for the complex structure, its degradation is complex and changeable, so the decision optimization problem is very complex, which is worthy of further study.

\section{Data Availability}

The data used to support the findings of this study are included within the article.

\section{Conflicts of Interest}

The authors declare that they have no conflicts of interest.

\section{References}

[1] Y. Yoon and M. Hastak, "Condition improvement measurement using the condition evaluation criteria of concrete bridge decks," Journal of Transportation Engineering, vol. 142, 2016.

[2] D. M. Frangopol and D. Saydam, "Structural performance indicators for bridges," in Bridge Engineering Handbook, 
W.-F. Chen and L. Duan, Eds., pp. 185-206, CRC Press, Boca Raton, FL, USA, 2nd edition, 2014.

[3] D. Honfi, I. Björnsson, O. L. Ivanov et al., "Informed successive condition assessments in bridge maintenance," Journal of Civil Structural Health Monitoring, vol. 10, pp. 729-737, 2020.

[4] J. Bian, F. Zhu, and Y. Kang, "A review on decision-making of service bridge maintenance and reinforcement based on reliability," Chinese and Foreign Highways, vol. 28, no. 1, pp. 133-138, 2008.

[5] J. Qin, X. Liu, Y. Zuo, and J. Wang, "Effects of optimal reliability selection model and economic benefits and maintenance strategies on structural," Journal of Rock Mechanics and Engineering, vol. 24, no. 1, pp. 97-104, 2005.

[6] X. Shao, J. Peng, and B. Yan, "Cost optimization of maintenance scheme for degraded bridge," Reliability Engineering Mechanics, vol. 25, no. 9, pp. 149-155, 2008.

[7] A. Arzhang, P. Shahram, and M. F. Christopher, "Probabilistic performance-based optimal design of steel moment resisting frames II: applications," Journal of Structural Engineering, vol. 133, no. 6, pp. 767-776, 2007.

[8] B. Fabio, B. Franco, M. F. Dan et al., "Probabilistic service life assessment and maintenance planning of con-crete structure," Journal of Structural Engineering, vol. 132, no. 5, pp. 810-825, 2006.

[9] G. F. Sirca, H. Adeli and F. Asce, Cost optimization of prestressed concrete bridges," Journal of Structural Engineering.ASCE, vol. 131, no. 3, pp. 0733-9445, 2005.

[10] M. Cao, S. Zhang, H. Chen, and Q. Huang, "A study on multiobjective optimization method for bridge maintenance decision," Chinese and Foreign Highways, vol. 33, no. 5, pp. 93-97, 2013.

[11] J. X. Peng, Macroscopic Characteristics of Dense Road Networks, The University of Hong Kong, HongKong, China, 2013.

[12] National Development and Reform Commission and Ministry of Construction, Methodology of Economic Evaluation and Parameters for Construction Projects, China Planning Press, Beijing, China, 2006.

[13] A. Farahani, H. Wallbaum, and J. O. Dalenbäck, "Cost-optimal maintenance and renovation planning in multifamily buildings with annual budget constraints," Jounal of Construction Engineering and Management, vol. 146, no. 3, 2020.

[14] S. Soheil and A. Payam, "Life-cycle cost optimization of semiactive magnetorheological dampers for the seismic control of steel frames," vol. 29, no. 18, Article ID e1807, 2020.

[15] M. Feng and Z. Zhao, "Methodology of bridge engineering operation and maintenance," Engineering Research - Engineering in an Interdisciplinary Perspective, vol. 8, no. 6, pp. 644-653, 2016.

[16] J. K. Vriling, H. G. Voortman, and M. D. Pandey, "A framework for risk criteria for critieal infraslruetures. Fundaroentals and case studies in The Netherlands," Journal of Risk Research, vol. 7, no. 6, pp. 569-579, 2003.

[17] P. H. Bottelberghs, "Risk analysis and safety policy developments in The Netherlands," Journal of Hazardous Materials, vol. 71, no. 1-3, pp. 59-84, 2000.

[18] T. Vrouwenvelder, "Stochasite modeling of extreme aetion eventsin structural engineering," Probabilistie Engineering Mechanies, vol. 15, no. 15, pp. 109-111, 2000.

[19] A. Chen, Y. Pan, D. Wang, and R. Ma, "Bridge maintenance and security in the big data age," Shanghai Highway, vol. 1, no. 01 , pp. 17-23, 2014.
[20] D. M. Frangopol and S. Kim, Life-Cycle of Structures under Uncertainty: Emphasis on Fatigue-Sensitive Civil and marine Structures, CRC Press, Bocaraton, FL, USA, 2019.

[21] D. Collings, "An environmental comparison of bridge forms," Proceedings of the Institution of Civil Engineers, vol. 12, pp. 163-168, 2006.

[22] J. S. Kong and D. M. Frangopol, "Life-cycle reliability-based maintenance cost optimization of deteriorating structures with emphasis on bridges," Journal of Structural Engineering, vol. 129, no. 6, pp. 818-828, 2003.

[23] J. S. Kong and D. M. Frangopol, "Cost-reliability interaction in life-cycle cost optimization of deteriorating structures," Journal of Structural Engineering, vol. 130, no. 11, pp. 17041712, 2004.

[24] K. Imai and D. M. Frangopol, "System reliability of suspension bridges," Structure Safety, vol. 24, no. 4, pp. 219-259, 2002.

[25] X. Shao, J. Peng, and B. Yan, "Cost optimization of maintenance scheme for degraded bridge based on reliability," Engineering Mechanics, vol. 197, no. 9, pp. 149-155, 2008.

[26] X. Liang, Research on the Risk Management Method of Bridge Operation Safety, Chang'an University, X'ian China, 2018.

[27] A. Kamel M, "Quantification of benefits of steel fiber reinforcement for rigid pavement," Materials Science, vol. 4, no. 6, pp. 189-198, 2016.

[28] Y. Sun and Y. Cao, "Development and application of rapid repairing materials in cement concrete deck repair," Highway, vol. 60, no. 6, pp. 218-223, 2015.

[29] X. Shao and X. Liu, "Relationship between probability-based bridge deterioration model and maintenance strategy," Journal of Chongqing Jiaotong University (Natural Science Edition), vol. 26, no. 5, pp. 32-36, 2007. 